\title{
A Comparison of Manual vs. Online Grading for Solid Models
}

\section{Holly K. Ault Ph.D., Worcester Polytechnic Institute}

Holly K. Ault received her BS, MSME and Ph.D. degrees from Worcester Polytechnic Institute in 1974, 1983 and 1988 respectively. She has worked as a Manufacturing Engineer for the Norton Company and Product Development Engineer for the Olin Corporation. She is currently Associate Professor of Mechanical Engineering atWorcester Polytechnic Institute, co-director of the Assistive Technology Resource Center, and director of the Melbourne Global Project Center. In the fall of 2001, she was invited as the Lise Meitner Visiting Professor, Department of Design Sciences, Lund Technical University, Lund, Sweden. Her primary teaching and course development responsibilities include undergraduate and graduate level courses in computer-aided design, mechanical design and rehabilitation engineering. She served as the Director of Liaison for the Engineering Design Graphics Division of ASEE from 1995-8, EDGD Program Chair for the ASEE Annual Conferences in 2002 and 2011, division vice chair in 2003 and division chair in 2004. Her teaching and research interests include computer aided mechanical design, geometric modeling, kinematics, machine design and rehabilitation engineering. She is a member of ASME, ASEE and ISGG.

\section{Mr. Alister Fraser, Parametric Technology Corp.}

Alister Fraser is the Senior Academic Program Manager for PTC. In his role at PTC Alister focuses on bringing together global leaders in product development and partnering them with colleges of engineering. These partnerships encourage industry and academic collaboration, create meaningful project experiences and foster cross-educational programs focused on product development education. In recognition of his experience in the field of computer aided design pedagogy Alister has been invited to participate on advisory boards including Digital Design and Technology Uk, Design Council UK, NASA additive manufacturing workforce development consortium and is a proud Co-Founder of the Strategic Partners for the Advancement of Collaborative Engineering (SAPCE) in association with NASA Glenn Research Center. Prior to working at PTC Alister was as a University teacher at the Department of Design and Technology, Loughborough University, UK, where he undertook his $\mathrm{PhD}$ on the topic of Computer Aided Design and its influence on pupil attainment. 


\title{
A Comparison of Manual vs. Online Grading for Solid Models
}

\begin{abstract}
A comparison between automated and manual grading of selected part files using the PTC Precison LMS system is presented. A pilot study was conducted to create an automatically graded assessment for a single part file with moderate complexity. Part files created by students in an intermediate level solid modeling course were graded manually and with the automatic system. This paper compares the output from grading as well as the effort required to implement the automated grading procedure. Results indicate that automatic grading can be used to assess a wide variety of model features and evaluate both procedural and strategic knowledge in solid modeling applications.

\section{Introduction}

Learners of skilled tasks such as CAD require the development of both declarative knowledge (knowing what) and procedural knowledge (knowing how). In the context of solid modeling, declarative knowledge would include facts such as the types of features that can be used to build a solid model, the types of geometric constraints used to control sketches, dimensioning rules, etc. Most current engineering graphics texts include this type of information ${ }^{1,2}$. Procedural knowledge focuses on how to perform various functions or utilize the commands in a particular solid modeling system. This type of information can be found in any of the typical introductory CAD tutorial texts or manuals ${ }^{3-5}$, as well as online learning available from the software vendors ${ }^{6,7}$ or independent sources such as YouTube ${ }^{8}$.

More importantly, effective use of CAD systems also requires the acquisition of strategic knowledge such as selection of solid modeling alternatives and proper use of modeling constraints to capture design intent ${ }^{9-11}$. This strategic knowledge requires higher level thinking skills associated with decision making, or knowing about available alternatives and how to choose between these alternatives.

Solid modeling learners also require certain skills that may also be included in basic CAD courses, such as the ability to read engineering drawings, 3D visualization skills, knowledge of manufacturing processes and basic computer literacy.

Solid Modeling Learning Objectives

Learning objectives may vary depending on the course; however, most courses seem to focus on development of modeling skills or procedural knowledge, supported by declarative knowledge. This is reinforced by the content of typical textbooks and software tutorial manuals used to support coursework ${ }^{1-5}$. Typical procedural learning objectives for an introductory engineering design graphics course include the ability to create and constrain sketches, create various features, create assemblies, render models, and generate drawings from solid models ${ }^{12,13}$. Documentation of part modeling strategies using freehand sketches is also mentioned. For a second level course $^{12}$, the learning objectives included both procedural and strategic knowledge, 
including the ability to incorporate design intent using parameters, applying tolerances, building design tables, and more advanced feature modeling.

\section{Grading Criteria for Part Models}

Baxter ${ }^{14}$ evaluated solid part models to assess the students' ability to decompose parts into single features and evaluate relations between entities, amongst other criteria. For typical problems in an introductory solid modeling course, Baxter developed five grading criteria one of which was based on visualization and a second based on design intent or relations. An example of Baxter's grading criteria for a simple part is shown in Figure 1.

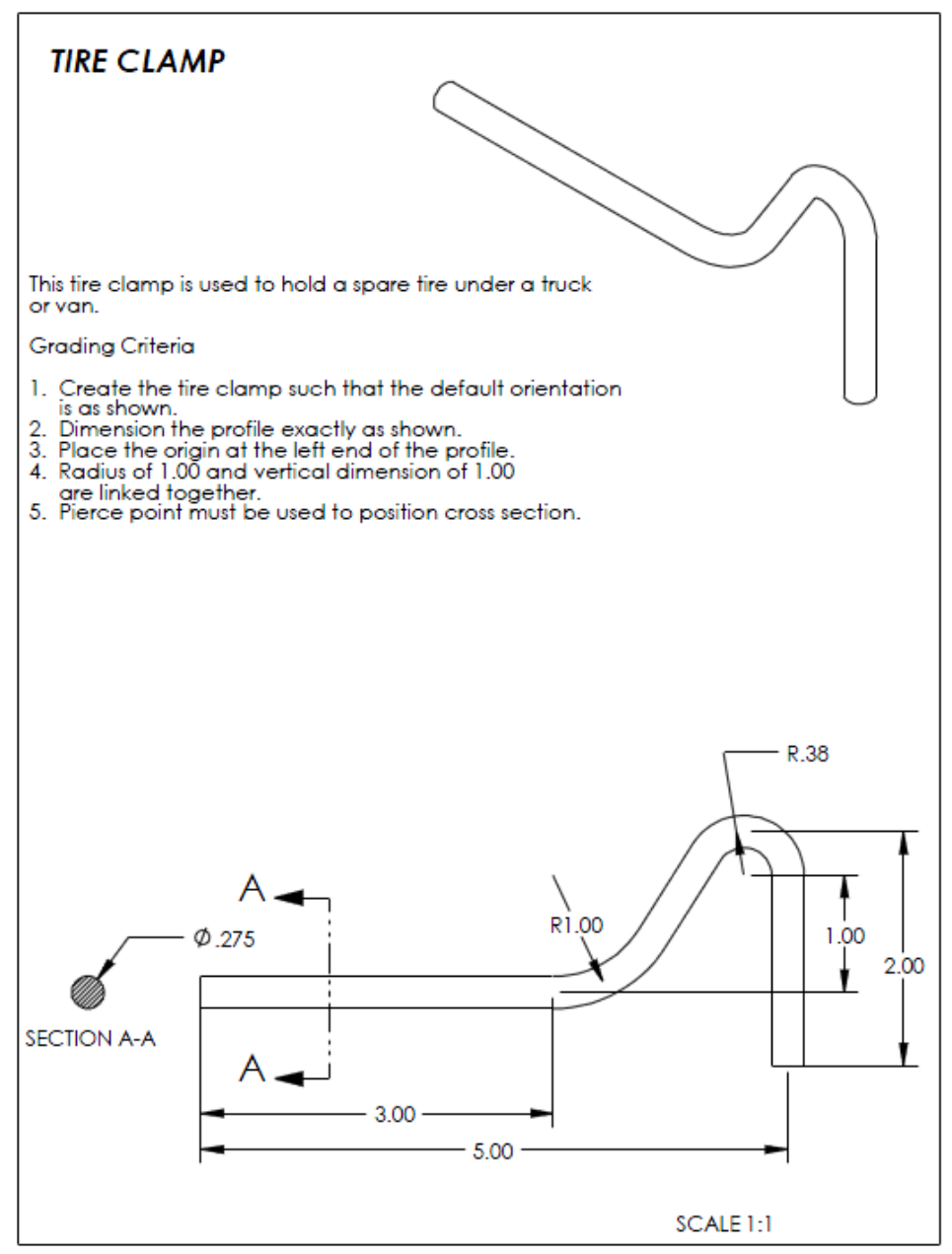

Figure 1. Grading criteria for a simple part ${ }^{14}$

Similarly, Table 1 lists the grading criteria used by Branoff ${ }^{12}$ for the trip lever shown in Figure 2. Note that this part is assigned in Branoff's second level CAD course, where model flexibility is required. 
Table 1. Grading Rubric for the TRIP LEVER ${ }^{12}$

\begin{tabular}{|l|l|}
\hline Description & Points \\
\hline Part dimensions are correct & 1 point \\
\hline Part orientation is correct & 1 point \\
\hline $\begin{array}{l}\text { Spotfaced hole remains centered when depth of part is } \\
\text { changed }\end{array}$ & 1 point \\
\hline Slot remains centered size is changed & 1 point \\
\hline $\begin{array}{l}\text { 9.5 diameter hole remains centered on tab when tab } \\
\text { depth is changed }\end{array}$ & 1 point \\
\hline Total & $\mathbf{5}$ points \\
\hline
\end{tabular}

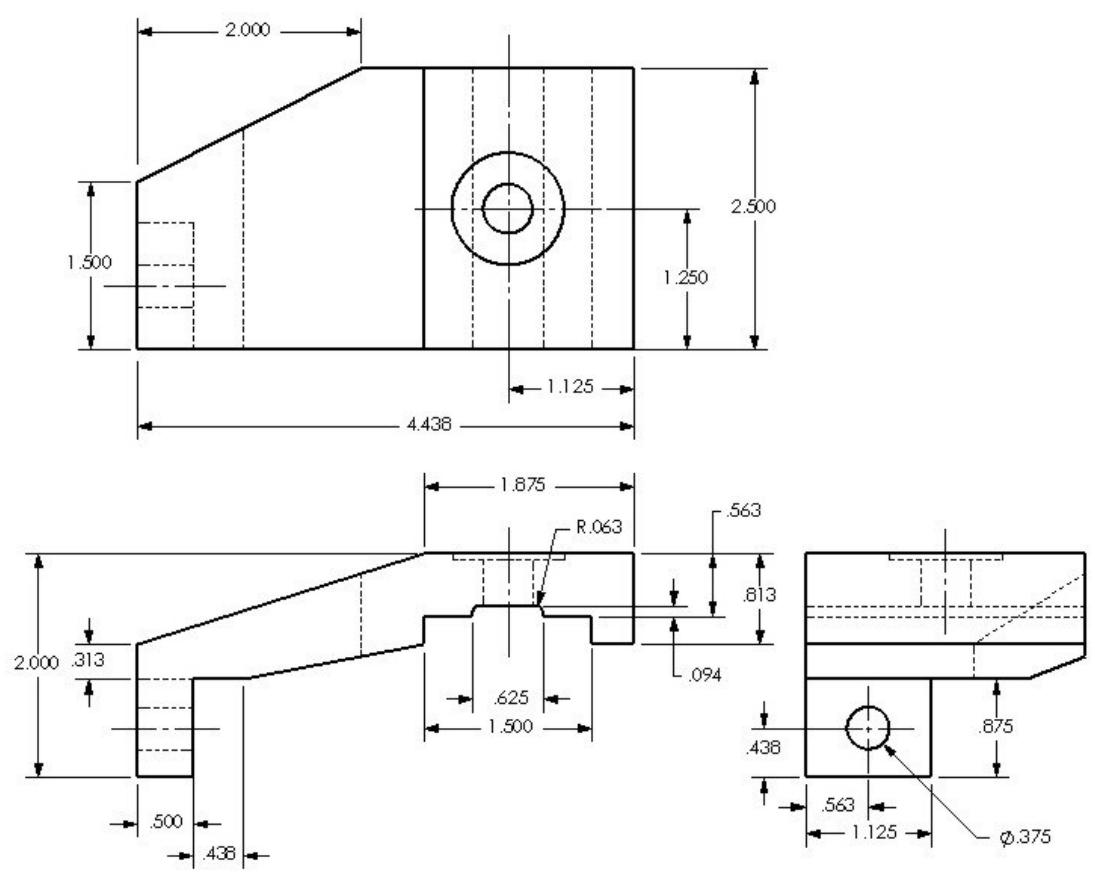

Figure 2. Trip Lever assigned in second level CAD course ${ }^{12}$

\section{Assessment of Solid Modeling Skills}

Rigorous assessment of students' solid modeling skills can be a time-consuming task for CAD instructors ${ }^{13,15}$. Students may submit print outs of parts (screen shots) to demonstrate that the parts were completed, and these screen shots may include a feature tree (model tree) that shows the selection and order of feature creation. However, many aspects of the modeling strategy cannot be examined by inspection of the feature tree alone. Parameters such as sketch dimensions and constraints, feature creation parameters, parent-child relations, and other factors that capture design intent are not easily checked except by examination of the part file. Manual checking of part files is a time-consuming task, and impractical for large classes. Thus, students tend to make parts that "look good", but fail to incorporate robust modeling strategies. Without feedback to remedy their models, students develop and perpetuate poor modeling practices ${ }^{9}$. The part models and grading criteria presented by Baxter ${ }^{14}$ and Branoff ${ }^{12,15}$ would require manual grading through examination of the part files. 
Wiebe et al. ${ }^{16}$ have proposed using dynamic modeling, or the assessment of part files based on changes to critical dimensions (aka "flexing" the model), as a means of checking the validity of solid models. Menary ${ }^{10}$ used interviews and/or video submissions to assess students' strategic knowledge of CAD. Both of these methods, while they can provide immediate feedback to students, are extremely time consuming and impractical for large classes.

\section{Automated Grading}

Limited attempts have been made to automate grading of solid models. Baxter ${ }^{17}$ used Visual Basic in conjunction with CAD software programming capabilities to query the database of student part files. Dassault Systems ${ }^{18}$ uses the calculated mass properties values of SolidWorks models to check the geometric accuracy of parts modeled for their certification exams. These attempts are either limited in the ability to assess the model and/or require extensive knowledge of the software and programming skills to develop assessment tools for specific parts. The tools are not generic and cannot be applied to models of different parts.

In this paper, we introduce the use of Pro/FICENCY, a PTC technology designed to automate the assessment of a student's hands-on modeling skills of parts, assemblies, and drawings, and ProToolkit, a programming utility within the solid modeling system, in an effort to identify variations and mistakes, and thereby automatically assess students' modeling strategies.

\section{Pipe Flange Model}

The pipe flange shown in Figure 3 was selected for a pilot study for the development of an automatically graded assessment using the PTC Precision LMS (Learning Management System). The part is modeled using Creo 1.0 and submitted to the grading engine in Precision LMS for automated grading.
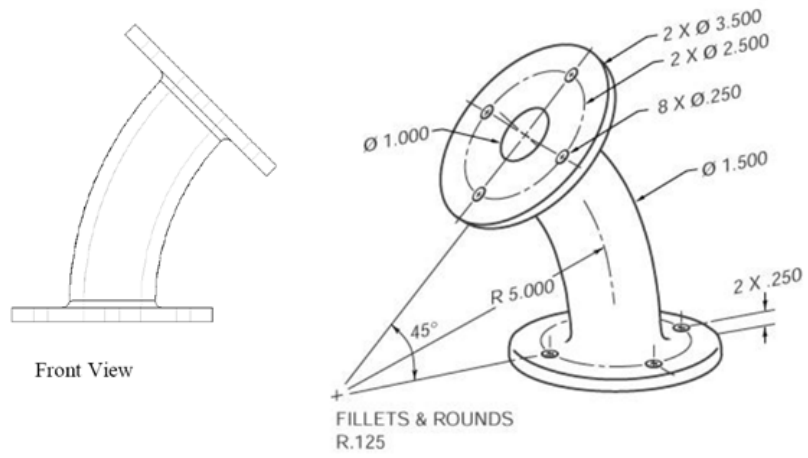

Figure 3. Pipe Flange used for Automated Grading

Grading criteria for the pipe flange include the proper selection of features, placement in the global coordinate system, and correct use of dimensioning. Students are instructed to model the part such that the specified front view is generated, and place the global origin at the center mark shown on the left side of the pictorial view. Students are further instructed to use good modeling 
strategies for a robust part model, and to minimize the number of features. No additional instructions are given; students must select appropriate features, order of feature creation, constraints and dimensioning schemes.

A variety of methods will produce the correct geometry, but only some of these approaches would reflect best practices in modeling strategies, which the students must demonstrate to get full credit for the assignment. For this part, it was expected that the model would be created using a single revolve feature for the body of the elbow, two extrusions for the flanges, a diametrally placed hole as the leader for a patterned hole set on each flange, and a single round feature. The internal diameter of the elbow feature and the flange features should be linked such that changing the independent feature would cause the dependent features to adjust accordingly.

Note that there are several options that students might choose to create a robust solid model. For example, the student might create the base flange before revolving the body of the elbow. The upper flange could be created on the end surface of the elbow revolve, or could be created as a mirror copy of the base flange (with or without the holes and/or round feature), requiring a mirror plane at $22.5^{\circ}$ from the horizontal datum plane. Dependency of feature dimensions on the flanges can be included as relations (equations) or through the mirror function.

Similarly, there are several options that would create the proper geometry but would not reflect best practices. For example, students might choose a sweep feature for the elbow, which is unnecessarily complex as compared to the simple revolve. Holes might be created using extruded cut features instead of the hole function, thereby failing to incorporate design intent and manufacturing knowledge into the model.

As can be seen from these options, simple visual inspection of the part geometry and model tree (feature list) does not reveal the relationships and dependencies between feature parameters. Correct geometry and placement in the world coordinate system can be determined based on the mass properties. Although this is an easy check to determine if the part geometry is $100 \%$ correct, due to the global nature of these properties, it is difficult to determine the cause of specific modeling errors that lead to incorrect solutions, and does not reveal poor modeling strategies such as the use of cut extrusions instead of using the hole function.

The multitude of options, both for correct and incorrect solutions, leads to a complex grading situation, where the instructor must carefully evaluate each individual part. Criteria for the both manual and automatic grading must be specific and measurable. Use of a grading rubric such as those suggested by Baxter ${ }^{14}$ and Branoff ${ }^{12}$ are necessary to quickly assess parts and provide consistency and feedback to students. Automating this process requires either complex algorithms or can be simplified to include only specific aspects of the modeling exercise that are the focus of current lesson ${ }^{14}$.

\section{Manual Grading Procedure}

The pipe flange was given as part of an online quiz during the third week of a second level solid modeling course for ME students in spring 2012. Manual grading of the part was based on the criteria listed in Table 2. The instructor manually opened each part and examined each of the features as well as selected sketches and feature parameters, based on the choice and order of 
features in the model tree. Comments were provided to the students by individual emails. Grading time averaged 5-6 minutes per part.

Automatic Grading Procedure

Automated grading using the grading engine in Precision LMS compares the student's model to a template supplied by the instructor. The automatic grading algorithm can be based on the presence or absence of various feature types, feature count, dimensional values within specified features, order of feature creation, global part properties such as mass, volume, or location of the center of gravity, etc. Point values are assigned for each grading check. The automated grading system allows the instructor to create multiple correct model solutions as well as multiple incorrect model solutions for comparison with the submitted student model file.

Table 2. Manual Grading Rubric for the Pipe Flange and Sample Feedback to Students

\begin{tabular}{|c|c|c|c|}
\hline Description & Points & Feedback Student 1 & Feedback Student 2 \\
\hline Correct geometry & 1 point & incomplete $-1 / 2$ & yes \\
\hline Appropriate choice and order of features & 2 points & $\begin{array}{l}\text { ok so far, but not } \\
\text { optimal }\end{array}$ & good \\
\hline Proper location of origin & 1 point & no -1 & yes \\
\hline Proper view orientation & 1 point & no -1 & yes \\
\hline $\begin{array}{l}\text { Use diameter and radius dimensions } \\
\text { correctly }\end{array}$ & 1 point & ok & yes \\
\hline $\begin{array}{l}\text { Hole placement correct (diametral } \\
\text { dimensioning, radial pattern) }\end{array}$ & 2 points & $\begin{array}{l}\text { patterning ok; the bolt } \\
\text { holes should be } \\
\text { HOLES (not extrude } \\
\text { cuts), placed using } \\
\text { diametral } \\
\text { dimensioning }-1-1 / 2\end{array}$ & $\begin{array}{l}\text { pattern ok; leader } \\
\text { hole should be placed } \\
\text { using diameter of bolt } \\
\text { hole circle }-1\end{array}$ \\
\hline $\begin{array}{l}\text { Use reference geometry for dependent } \\
\text { features }\end{array}$ & 1 point & no evidence & $\begin{array}{l}\text { pick up } 1 " \text { dia circle } \\
\text { from revolve to create } \\
\text { extrude cuts in flanges } \\
-1 / 2\end{array}$ \\
\hline General modeling strategy & 1 point & poor-fair $-1 / 2$ & \\
\hline Comments & & $\begin{array}{l}\text { simple revolve could } \\
\text { be used instead of } \\
\text { sweep }\end{array}$ & \\
\hline Total & 10 points & $5-1 / 2$ & 8-1/2 \\
\hline
\end{tabular}

For the pipe flange, the grading engine in Precision LMS checked for the presence of two extrude features, one revolve feature, eight holes, and two patterns. Specific dimensions within the revolve feature and the hole pattern leader were inspected. The proper placement of the model was determined by checking the part volume and location (xyz coordinates) of the center of gravity. Templates for the grading rubric, including the problem statement, a list of the grading criteria, files for comparison of correct and incorrect solutions, and suggested feedback were created by the course instructor. Becoming familiar with the the Precision LMS grading system and preparing the template required approximately one day's worth of effort. Creation of the grading file was completed by the PTC University Systems Product Manager and required a few hours of effort. 
For this pilot study, all of the student files from the spring 2012 class were submitted to the grading engine in Precision LMS by the instructor. Results of the automated grading of the part files for Students 1 and 2 are shown in Tables A1 and A2 in the Appendix. This feedback is designed by the instructor and embedded in the Precision LMS grading system. Feedback can be customized depending on the results given. For example, when checking the mass properties, the first check reveals whether the volume is correct, and reports differences if found. If the volume is correct, the part is then checked to determine if the center of gravity is in the proper location. Thus, feedback for the last item in the grading report could include either a comparison of incorrect volume or CG location, depending on the student's error. Table A3 shows an example of the solution details which would be provided to the student after submission of the part for grading, with step-by-step instructions for creating an acceptable solution.

\section{Discussion}

Our goals for this pilot study were to investigate the use of the automatic grading system with existing parts and assess its capabilities for future implementation. We wanted to test the robustness of the grading algorithm using a wide variety of parts created by students. We used existing part files from a previous semester for comparison of manual vs. automatic grading of the part files. The grading criteria were somewhat different from the original criteria used to manually grade the parts. Some of the original criteria were either subjective (appropriate choice and order of features, general modeling strategy) or combined multiple measures for assessment (overall correct use of diameter and radius dimensions). A direct comparison of the numeric results of automatic vs. manual grading was not feasible in this study due to the disparity between criteria used in the grading algorithms. The parts were not manually regraded using new grading criteria. However, it is clear that the system is capable of assessing strategic knowledge as well as procedural CAD "skills", depending on the specific criteria selected by the instructor for assessment.

A total of 42 student parts were submitted to the system for automatic grading. Online automatic grading of the files was completed in approximately 30 seconds. In practice, the part submission would be done by the student, so no time is required of the instructor. Students can receive immediate feedback on their solutions. In addition to the results from each grading check, the student can be provided with hints, modeling methods, steps, or any other desired feedback, either for specific errors or for a general solution to the modeling exercise. Thus, in addition to its use in grading quizzes for summative assessment, the online automated grading could be used to develop tutorials, allowing multiple submissions until the student generates an acceptable model. Simpler models with only one or two features could also be developed for use in tutorial applications.

Many of the students in this particular cohort chose to use a sweep feature instead of the revolve feature for the elbow section of the pipe flange. This resulted in many low scores, since several of the dimensional checks searched for dimensions within a revolve feature, which did not exist in parts with a swept feature for the pipe elbow. With manual grading, the dimensional checks can be accomplished regardless of feature selection. More complex coding within the automated system may be needed to implement logic statements which would achieve the same results. This suggests that developers and instructors need to think carefully about the grading criteria and 
checks that are programmed, and devise checks that are flexible enough to accept alternative modeling strategies when appropriate.

\section{Conclusion}

Automated grading with PTC's Precison LMS can be used to evaluate many of the grading criteria specified by CAD educators ${ }^{12,14}$. We did not test whether the system could evaluate results of changing the model dimensions as suggested by Wiebe et al. ${ }^{16}$ for dynamic modeling, however, the capability does exist within the model checking system. The time required to set up a grading model does not appear to be excessive, and could be well worth the effort, especially for large classes. Our next step is to investigate whether the programming tasks can be easily accomplished by instructors or graduate students.

Results indicate that the automatic grading can be used successfully to provide consistent feedback on part models and reduce or eliminate grading time. Automatic grading can be used to assess many different modeling criteria, including but not limited to the proper selection and placement of features, feature order, and use of constraints to capture design intent. The criteria used to check the solid model can be selected to assess both procedural and strategic knowledge. Future work will involve implementation of automatic grading for quizzes, homework exercises and/or online tutorials. We will design a range of skills assessments using the Precision LMS system and evaluate improvements in the students' modeling skills. Grading of dynamic systems may also be investigated.

Bibliography

${ }^{1}$ Lieu, D. and S. Sorby (2008), Visualization, Modeling, and Graphics for Engineering Design, Delmar Cengage Learning.

${ }^{2}$ Bertoline, G. R. \& Wiebe, E. N. (2002). Fundamentals of Graphics Communication. 3rd Edition. Boston: McGraw-Hill.

${ }^{3}$ Toogood, R. (2012). Advanced Tutorial for Creo Parametric 1.0 \& 2.0, Schroff Development Corp.

${ }^{4}$ Rider, M. (2013). Designing with Creo Parametric 1.0. McGraw-Hill, New York.

${ }^{5}$ Planchard, D. and M. Planchard (2012). SolidWorks 2012 Tutorial. Schroff Development Corp.

${ }^{6}$ Parametric Technologies Corporation (PTC) (2012). http://www.ptc.com/ Accessed 11 July 2012.

${ }^{7}$ Solidworks (2012). http://www.solidworks.com/ Accessed 11 July 2012.

${ }^{8}$ YouTube (2013). http://www.youtube.com/ Accessed 03 January 2013

${ }^{9}$ Chester, I. (2007) Teaching for CAD Expertise. International Journal of Technology and Design Education, Volume 17, Number 1 (2007), 23-35.

${ }^{10}$ Menary, G. and T. Robinson (2011). Novel approaches for teaching and assessing CAD. International Conference on Engineering Education, Belfast, N. Ireland, 21-26 August 2011.

${ }^{11}$ Rynne, A., and W. Gaughran (2012). Cognitive Modeling Strategies for Optimum Design Intent in Parametric Modeling. Computers in Education Journal, Vol. 18 No. 1, pp. 55-68. 
${ }^{12}$ Branoff, T.J. (2004). Constraint-Based Modeling in the Engineering Graphics Curriculum: Laboratory Activities and Evaluation Strategies. Proc. Midyear Conf. Eng. Design Graphics Division of the Am. Soc. for Eng. Education, pp. 132-138, 2004.

${ }^{13}$ Elrod, D. \& Stewart, M. D. (2004). Assessing student work in engineering graphics and visualization course. Proceedings of the 2004 Annual Conference of the American Society for Engineering Education, Salt Lake City, Utah, June 20-23, 2004.

${ }^{14}$ Baxter, D. (2002), Evaluating Student Performance in a Freshman Graphics Course to Provide Early Intervention for Students with Visualization and/or Design Intent Difficulties, ASEE Annual Conference, 2002.

${ }^{15}$ Branoff, T., E. Wiebe and N. Hartman (2003). Integrating Constraint-Based CAD into an Introductory Engineering Graphics Course: Activities and Grading Strategies. ASEE Annual Conference 2003.

${ }^{16}$ Wiebe, E., T. Branoff, and N. Hartman (2003). Dynamic Modeling with Constraint-based CAD in Introductory Engineering Graphics. ASEE Annual Conference, 2003.

${ }^{17}$ Baxter, D. and M. Guerci (2003), Automating an Introductory Computer Aided Design Course to Improve Student Evaluation, ASEE Annual Conference, 2003.

${ }^{18}$ Dassault Systems (2012) MCAD Certification Programs, http://www.solidworks.com/sw/support/mcadcertification-programs.htm 


\section{Appendix}

Table A1. Automatic grading results for Student 1.

\begin{tabular}{|c|c|c|c|c|}
\hline Result & Score & $\begin{array}{c}\text { Check } \\
\text { Description }\end{array}$ & Expected Result & Actual Result \\
\hline$\checkmark$ & \begin{tabular}{|l||}
$10 \% / / \mid$ \\
$10 \%$
\end{tabular} & $\begin{array}{l}\text { Verify the } \\
\text { number of } \\
\text { new extruded } \\
\text { features }\end{array}$ & $\begin{array}{l}\text { Verify the total number of } \\
\text { new features in the model } \\
\text { q29668_pipe_flange.prt. }\end{array}$ & Correct \\
\hline$x$ & $\begin{array}{l}0 \% / \\
10 \%\end{array}$ & $\begin{array}{l}\text { Verify the } \\
\text { number of } \\
\text { new revolved } \\
\text { features }\end{array}$ & $\begin{array}{l}\text { Verify the total number of } \\
\text { new features in the model } \\
\text { q29668_pipe_flange.prt. }\end{array}$ & $\begin{array}{l}\text { The model } \\
\text { q29668_pipe_flange.prt } \\
\text { contains an incorrect number } \\
\text { of features. }\end{array}$ \\
\hline$x$ & $\begin{array}{l}0 \% / \\
10 \%\end{array}$ & $\begin{array}{l}\text { Verify the } \\
\text { number of } \\
\text { new hole } \\
\text { features } \\
\end{array}$ & $\begin{array}{l}\text { Verify the total number of } \\
\text { new features in the model } \\
\text { q29668_pipe_flange.prt. }\end{array}$ & \begin{tabular}{|l|} 
The model \\
q29668_pipe_flange.prt \\
contains an incorrect number \\
of features. \\
\end{tabular} \\
\hline$\checkmark$ & \begin{tabular}{|l||}
$10 \% / /$ \\
$10 \%$
\end{tabular} & $\begin{array}{l}\text { Verify the } \\
\text { number of } \\
\text { new pattern } \\
\text { features }\end{array}$ & $\begin{array}{l}\text { Verify the total number of } \\
\text { new features in the model } \\
\text { q29668_pipe_flange.prt. }\end{array}$ & Correct \\
\hline$x$ & $\begin{array}{l}0 \% / \\
5 \%\end{array}$ & $\begin{array}{l}\text { Verify feature } \\
\text { dimensions }\end{array}$ & $\begin{array}{l}\text { Verify the dimension, 1.5, } \\
\text { exists in feature ID } 7 .\end{array}$ & $\begin{array}{l}\text { The dimension value } 1.5 \\
\text { cannot be found. }\end{array}$ \\
\hline$x$ & $\begin{array}{l}0 \% / \\
5 \%\end{array}$ & $\begin{array}{l}\text { Verify feature } \\
\text { dimensions }\end{array}$ & $\begin{array}{l}\text { Verify the dimension, 5.0, } \\
\text { exists in feature ID } 7 .\end{array}$ & $\begin{array}{l}\text { The dimension value } 5.0 \\
\text { cannot be found. }\end{array}$ \\
\hline$x$ & $\begin{array}{l}0 \% / \\
5 \%\end{array}$ & $\begin{array}{l}\text { Verify feature } \\
\text { dimensions }\end{array}$ & $\begin{array}{l}\text { Verify the dimension, 45.0, } \\
\text { exists in feature ID } 7 .\end{array}$ & $\begin{array}{l}\text { The dimension value } 45.0 \\
\text { cannot be found. }\end{array}$ \\
\hline$\checkmark$ & $\begin{array}{l}5 \% / \\
5 \%\end{array}$ & $\begin{array}{l}\text { Verify feature } \\
\text { dimensions }\end{array}$ & $\begin{array}{l}\text { Verify the dimension, } 3.5, \\
\text { exists in feature ID } 46 .\end{array}$ & Correct \\
\hline$\checkmark$ & \begin{tabular}{|l}
$5 \% /$ \\
$5 \%$ \\
$5 \%$
\end{tabular} & $\begin{array}{l}\text { Verify feature } \\
\text { dimensions }\end{array}$ & $\begin{array}{l}\text { Verify the dimension, } 0.25 \text {, } \\
\text { exists in feature ID } 46 .\end{array}$ & Correct \\
\hline$x$ & $\begin{array}{l}0 \% / \\
35 \%\end{array}$ & $\begin{array}{l}\text { Verify model } \\
\text { geometry }\end{array}$ & Verify the model volume & $\begin{array}{l}\text { The model } \\
\text { q29668_pipe_flange.prt has } \\
\text { a volume of 11.7216. The } \\
\text { correct volume is } 8.20788 \text {. }\end{array}$ \\
\hline
\end{tabular}


Table A2. Automatic grading results for Student 2.

\begin{tabular}{|c|c|c|c|c|}
\hline Result & Score & $\begin{array}{c}\text { Check } \\
\text { Description }\end{array}$ & Expected Result & Actual Result \\
\hline$\checkmark$ & $\begin{array}{l}10 \% / \\
10 \%\end{array}$ & \begin{tabular}{|l||} 
Verify the number \\
of new extruded \\
features
\end{tabular} & \begin{tabular}{|l} 
Verify the total number of new \\
features in the model \\
q29668_pipe_flange.prt.
\end{tabular} & Correct \\
\hline$\checkmark$ & $\begin{array}{l}10 \% / \\
10 \%\end{array}$ & \begin{tabular}{|l||} 
Verify the number \\
of new revolved \\
features
\end{tabular} & \begin{tabular}{|l} 
Verify the total number of new \\
features in the model \\
q29668_pipe_flange.prt.
\end{tabular} & Correct \\
\hline$\checkmark$ & $\begin{array}{l}10 \% / \\
10 \%\end{array}$ & \begin{tabular}{|l||} 
Verify the number \\
of new hole \\
features
\end{tabular} & \begin{tabular}{|l} 
Verify the total number of new \\
features in the model \\
q29668_pipe_flange.prt.
\end{tabular} & Correct \\
\hline$\checkmark$ & $\begin{array}{l}10 \% / \\
10 \%\end{array}$ & \begin{tabular}{|l||} 
Verify the number \\
of new pattern \\
features
\end{tabular} & $\begin{array}{l}\text { Verify the total number of new } \\
\text { features in the model } \\
\text { q29668_pipe_flange.prt. }\end{array}$ & Correct \\
\hline$\checkmark$ & \begin{tabular}{|l|}
$5 \% /$ \\
$5 \%$ \\
\end{tabular} & \begin{tabular}{|l||} 
Verify feature \\
dimensions
\end{tabular} & $\begin{array}{l}\text { Verify the dimension, 1.5, exists in } \\
\text { feature ID } 87 .\end{array}$ & Correct \\
\hline$x$ & $\begin{array}{l}0 \% / \\
5 \%\end{array}$ & $\begin{array}{l}\text { Verify feature } \\
\text { dimensions }\end{array}$ & $\begin{array}{l}\text { Verify the dimension, 5.0, exists in } \\
\text { feature ID } 87 .\end{array}$ & $\begin{array}{l}\text { The dimension } \\
\text { value } 5.0 \text { cannot } \\
\text { be found. }\end{array}$ \\
\hline$\checkmark$ & $\begin{array}{ll}5 \% / \\
5 \% \\
5 \%\end{array}$ & \begin{tabular}{|l} 
Verify feature \\
dimensions
\end{tabular} & $\begin{array}{l}\text { Verify the dimension, 45.0, exists } \\
\text { in feature ID } 87 .\end{array}$ & Correct \\
\hline$\checkmark$ & \begin{tabular}{|l}
$5 \% /$ \\
$5 \%$ \\
$5 \%$
\end{tabular} & \begin{tabular}{|l} 
Verify feature \\
dimensions
\end{tabular} & $\begin{array}{l}\text { Verify the dimension, 3.5, exists in } \\
\text { feature ID } 52 .\end{array}$ & Correct \\
\hline$\checkmark$ & $\begin{array}{ll}5 \% / \\
5 \% \\
\end{array}$ & \begin{tabular}{|l} 
Verify feature \\
dimensions
\end{tabular} & $\begin{array}{l}\text { Verify the dimension, } 0.25 \text {, exists } \\
\text { in feature ID } 52 .\end{array}$ & Correct \\
\hline$\checkmark$ & \begin{tabular}{|l|}
$35 \% /$ \\
$35 \%$
\end{tabular} & \begin{tabular}{|l} 
Verify model \\
geometry
\end{tabular} & Verify the model geometry & Correct \\
\hline \multicolumn{5}{|c|}{ Total: $95 \%$} \\
\hline
\end{tabular}




\section{Table A3. Solution Feedback provided by LMS}

\section{Solution feedback}

This is an exercise in using proper modeling strategy. A correct model will exhibit appropriate feature selection, proper placement of the origin, proper sketch plane selection, use of reference geometry, correct use of hole placement options, patterning and fillets.

1. Use the Revolve feature to create the body of the elbow. Sketch on the Top datum plane with the center of two concentric circles along the -x axis at 5". Revolve 45 degrees about the $\mathrm{z}$ axis.

2. Use the Extrude command to create the bottom flange. Sketch the outer diameter on the top datum plane and use the internal edge of the elbow body for the center hole in the flange. Do not create a separate hole or cut feature for the center opening in the flange.

3. Create the top flange by sketching on the upper annular surface of the elbow body. Sketch the outer diameter and use the internal edge of the elbow body as in Step 2.

4. Place a hole on the bottom flange using diametral dimensioning. Pattern this hole. Repeat for the top flange.

5. Fillet the part along the inner and outer edges of the surface which extends from the elbow body on both flanges.

6. Alternate: Create the revolve feature and first flange as above. Create the hole pattern and fillet the edge between the flange and the elbow body. Group the flange, hole pattern and fillet. Create a datum plane through the z-axis and 22.5 degrees from the top plane. Mirror the grouped features across this datum plane. 